\title{
6
}

\section{The Role of Intercultural Communication Competency in Global Business Negotiations}

\footnotetext{
lobal considerations impact everyday business decisions for companies large and small. Should we buy this component part from a U. S. supplier, or consider sourcing outside the United States? Where should we produce, market, and sell our products and services? For most, it is a global market to consider. One only needs to examine the current and projected growth of international trade to clearly see the impact on our future.

Corporations are aware that to be successful in tomorrow's marketplace requires employees to be competent in communicating with those from other cultures. In the past, most international managers relied on general cultural guidelines for conducting intercultural
} 
negotiations. However, the increase in global trade transactions has resulted in integrated cultural exchanges, new cultural partnerships, and unique cultural interactions, making old, superficial generalities less accurate. One effect of increasing multicultural interactions is a change in homogenous cultures or, indeed, nations. A new culture of world trade is born. Research offered to explain communication based on cultural generalities is helpful but quickly becoming dated and insufficient for providing guidelines for negotiating with other cultures. As discussed in previous chapters, culture is defined by most as socially transmitted beliefs, values, behavioral patterns, norms, and rituals that are shared by a large group of people or a community (Cai, Wilson, \& Drake, 2000; Hofstede, 1980; Salacuse, 1991). Communicating interculturally is the process whereby individuals from different cultures attempt to exchange information and interpret or understand the other person. We propose in this chapter that successful intercultural negotiation is not only influenced by an understanding of general cultural knowledge, but also, and more important, by the negotiators' competency in intercultural communication.

This chapter examines intercultural communication competency (ICC) in geocentric business negotiations. We present key components of ICC specific to the success of intercultural business transactions. An examination of how these key components specifically affect global business negotiations is included. We also offer 12 guidelines for enhancing communicative behavior in intercultural business negotiations.

\section{* overvieW of intercultural COMMUNICATION COMPETENCY}

Intercultural communication competency grew out of the interpersonal communication competency research. The contextual distinctiveness of the intercultural interaction is a unique communication competency issue. It is possible that an individual may be highly competent in communicating with others in his or her own culture but not competent when interacting with others who are culturally different. In the past decade, numerous books, articles, and papers have been published on intercultural competency (Gudykunst, 2005; Hampden-Turner \& Trompenaars, 2000; Landis, Bennett, \& Bennett, 2004).

To understand ICC, we first take a brief look at communication competency in general. Spitzberg and Cupach (1984) define communication competency as the ability to achieve your goals while you fulfill relational and situational expectations (as cited in Cupach \& Canary, 
1997). Spitzberg and Cupach contend that communication competency is primarily comprised of two dimensions, appropriateness (meeting social expectations and social rules) and effectiveness (achieving one's goals). Although the previous communication competency research is helpful (Cupach \& Canary, 1997; Snavely \& Walters, 1983; Wiemann, 1977), it is predominantly restricted to general intracultural settings and is not specific to global negotiation. Thus, a void remained in explaining intercultural negotiation for business transactions.

Understanding the individual's role in ICC has gained the attention of several researchers (Gudykunst, 1998; Ting-Toomey, 1988). The focus of ICC has remained in the forefront for understanding intercultural relationships. Questions concerning how to be effective in our messages with others outside our cultural boundaries led to the development of intercultural communication competency. Gudykunst as well as others (Klopf, 2001; Ting-Toomey, 1988) have given us a framework for examining the role that general cultural dimensions play in the communication process. Gudykunst, in his 1998 book titled Bridging Differences: Effective Intergroup Communication, concludes that "culture influences our communication and our communication influences our cultures" (p. 44). Therefore, an individual's ICC is important in providing communication guidelines for how specific cultures and nations talk. Neither cultural level of competency nor the individual level of competency is adequate to reflect the new multicultural phenomena occurring in our global market. Therefore, a richer understanding of global negotiation will result from an integrative approach (individual factors and cultural factors). Thus, viewing ICC in business negotiations offers important perspectives for the new global market.

Negotiator communication competency is essential for understanding the role that communication plays in global business negotiations. The benefits of moving from a cultural generality model to a geocentric model that includes the individual negotiators' ICC is greatly beneficial for several reasons.

First, negotiators stand their best chance of reaching an optimal agreement when the parties are able to engage in creative problem solving (Fisher, Ury, \& Patton, 1991). This problem-solving process often requires the parties to negotiate face to face (or in a dyadic context) and thus is a relational, context-based process in which sensitivity to the recipient's interpretation of a message is essential for shared meaning. Second, unlike other contextually based communication competency (e.g., classroom), global negotiations are heavily reliant upon the development of the parties' relationship. Therefore, examining global negotiations from a communication competency framework incorporates the 
development of the relationship through the dynamics of communication interactions. Finally, a communication competency approach offers an excellent foundation for building a more advanced model of how communication competency occurs during conflict episodes in the intercultural negotiation setting.

The nature of constructive conflict interactions requires that parties act in a highly appropriate and effective manner if they are to move beyond the point of conflict. For example, at conflict points in the negotiation process, it is essential to maintain face and provide face-saving gestures so that there are opportunities for parties to continue engaging in the negotiation process. The relationship of the negotiating parties is tested during conflict episodes, and it is often the face-to-face communication that frames the opportunities for further relationship development or the destruction of the relationship.

Thus, examining global negotiation and the role of ICC provides an excellent foundation for investigating the dynamics of success in global negotiation. Spitzberg and Cupach argue that ICC can be explained as appropriateness and effectiveness with more emphasis on contextual factors. We argue that appropriateness and effectiveness operate at the basic level for understanding ICC, but other factors must be included to fully understand ICC in geocentric negotiations.

We now turn to a more in-depth look at what factors influence ICC in global business negotiation. The key components for developing ICC in geocentric business negotiations are appropriateness, effectiveness, anxiety reduction, adaptation, face honoring and protection, sensitivity and empathy, mindfulness and presence, and knowledge. These components are discussed in the next section.

\section{Key Components of Intercultural Communication Competency (ICC)}

- Appropriateness

- Effectiveness

- Anxiety Reduction

- Adaptation

- Face Honoring and Protection

- Sensitivity and Empathy

- Mindfulness and Presence

- Knowledge 


\section{Appropriateness}

Appropriateness is the ability to communicate with someone in a socially sensitive manner so as not to offend or break any rules that would result in insult, face threat, or rudeness. Communication appropriateness involves considering a variety of strategies and the communication constraints that exist within a specific communication context. Message selection and strategy for communicating are guided by these constraints, or rules. Embedded in the cultural norms and rules is the appropriateness of certain types of behaviors and the manner in which we communicate. Philipsen's $(1992,1997)$ speech codes theory posits that in order to understand communication, one must understand the cultural speech codes ("a system of socially-constructed symbols and meanings, premises, and rules, pertaining to communicative conduct") (Philipsen, 1997, p. 126). The socially constructed symbols and meanings are culturally distinctive codes for interpreting and explaining intercultural communication. Therefore, when communicating in the international business negotiation context, one must consider the norms, rules, and expectations and how these are determined by an accumulation of culture and regional or subculture, organizational culture, and individual personality, as well as any previous negotiation experiences.

The international business negotiation context has specific constraints that should be considered in appropriate message selection. For example, global business negotiations typically entail procedural rules or guidelines offered to facilitate agreement. Parks (1985) states,

Competent communicators have a vested interest in maintaining the rules of social conduct because they realize, however dimly, that their ability to pursue their own goals depends on the freedom of others to pursue their goals. Personal control, then, is more often an ally of social appropriateness than its enemy. (p. 197)

Thus, it is important for the global business negotiator to keep in mind how the negotiation process (e.g., structural and procedural issues) is conducted. Also important are the type of business, the parties' relationship, the organizational culture (bureaucratic, lateral, highly structured, informal, etc.), individual style (argumentative, assertive, or passive), the position or role of the negotiator (buyer or seller), and the specific issues of the negotiation as guidelines for appropriate strategy selection. The appropriateness component of becoming a competent communicator in the global market is interrelated to other ICC factors discussed in the following paragraphs. 


\section{Effectiveness}

How we "effectively" achieve our goals is a vital part of the global business negotiation. Spitzberg and Cupach (1989) defined effectiveness as "successful goal achievement or accomplishment" (p. 7). How we attempt to reach effectiveness is related to our ability to maximize our rewards and minimize our costs. Effectiveness is the ability to achieve your goals through the communication process. Specifically, an individual must be able to maximize his or her potential for achieving his or her goals by selecting strategies that will allow the individual to achieve his or her success through interaction. Effective strategy selection is critical for clear communication in intercultural settings. M. Kim (1994) argues that strategic competency entails a person's ability to select an effective message that allows the other party to derive the intended meaning. However, Kim and Wilson (1994) conclude that "different cultural groups have drastically different ideas about what constitutes an effective strategy" (p. 229). Thus, any discussion of effectiveness must consider that cultural perspectives influence the strategy choice and perception of the effectiveness of that strategy.

Western cultures generally view efficiency, or time required to reach an agreement, as an important consideration in measuring effectiveness. However, this may not hold true for other cultures or individuals who do not share the same value of time.

For example, Schmidt Corporation, a manufacturing company headquartered in Germany, wants to obtain a contractual agreement to buy plastics from Paranhos Incorporated, headquartered in Brazil. Schmidt Corporation's negotiator, Ms. Gausser, is under a deadline to go to Brazil to meet with someone from Paranhos and be back home in time to meet with alternative vendors if she cannot reach an agreement with Paranhos Corporation. Ms. Gausser's time line, or what she considers to be efficient use of her time, is one week (based on how she usually conducts business). However, Paranhos Corporation's negotiator, Mr. de Aveiro, thinks that effective agreement has a time line of around 3 months (based on how he usually conducts negotiations). Mr. de Aveiro's goals for the meeting are to begin a relationship with Schmidt Corporation and Ms. Gausser, spend time getting to know each other and understand the other party's company, as well as show Ms. Gausser some of the culture and history of his country.

Goal attainment is not likely to be achieved for either negotiator because their perception of effective use of time is very different. This situation requires each negotiator to acquire an understanding of the other party's values and sense of business in order for either to be 
effective in achieving his or her goals. More than likely, each will leave dissatisfied, and a business opportunity may be lost.

There have been several studies that reveal specific cultural differences in interpreting effectiveness. For example, Kim and Wilson's (1994) study of cross-cultural request strategies revealed a difference between Americans' and Koreans' rating of effective strategy. They found that Americans rated direct statement requests as the most effective strategy, whereas Koreans rated it the least effective strategy. Thus, a global business negotiator must be sensitive to others' value of certain strategies as he or she attempts to succeed in reaching agreement.

\section{Anxiety and Uncertainty Reduction}

Uncertainty reduction theory (Berger \& Calabrese, 1975) suggests that we are likely to experience uncertainty about communicating with another individual, especially when we are unable to predict or explain a stranger's behaviors. This uncertainty (both predictive uncertainty and explanatory uncertainty), according to Gudykunst, results when we are interacting with someone different from us. Uncertainty hinders the quantity and quality of communication. The nature of international business transactions creates just this type of situation. When we are not able to predict the other's behaviors or attitudes (predictive uncertainty) and we are uncertain how to explain the other's behaviors (explanatory uncertainty), we experience high uncertainty and anxiety. The less certain we are about another individual's behaviors, the more anxious we are. The fast pace of the international market requires negotiators to tread into unfamiliar environments with little predictive knowledge of another's negotiation behavior. Anxiety and uncertainty are often reported when new markets open and new relationships must be established. However, it is also possible in international trade that the negotiator may become anxious about the other negotiator because he or she is aware of the other party's entrenched position. This anxiety based on known differences may cause the negotiator to become uncertain of how to communicate most effectively to achieve a positive outcome. In both experiences, the anxiety is related to our feelings and uncertainty is related to our cognitive processing ability. Gudykunst posits that we have "thresholds of uncertainty."

If our uncertainty is below our minimum threshold level, we will interact with strangers with a great deal of confidence (Gudykunst, 1998). Typically, when our uncertainty is below the threshold level, we act and believe that we can predict the other person's behavior and are 
in control of the interaction. When dealing with other cultures, this assumption is likely to result in misinterpretations, or worse, communication mistakes, such as face-threatening or insulting behavior. In the case of intercultural business negotiations, this can be devastating to the negotiation process, possibly resulting in a failure to reach agreement and an adverse effect on the relationship. The awareness or mindfulness of others in the communication process is lost (because we are assuming little attention is needed to communicate with the other), and the negotiator may be perceived as disinterested in the other party or even perhaps as exhibiting dislike or disdain for the other.

If uncertainty is above the maximum threshold level, Gudykunst argues we will not want to communicate with the stranger (or oppositional negotiator). The ideal range of uncertainty for communicating with someone from a different culture falls between the minimum and maximum threshold levels of uncertainty. Communicating in this range allows us to experience enough uncertainty to be motivated and open to new information about the other person with a level of comfort.

The anxiety we experience is related to our level of uncertainty. One way to evaluate our anxiety is to be cognizant of our physiological reactions, such as butterflies in our stomach, headache, sweaty hands, shortness of breath, or general nervousness. The issue for successful negotiation in the global business negotiation is being in the range of minimum to maximum threshold of uncertainty/anxiety. Similar to speech-making and test-taking experiences, having a certain amount of uneasiness and anxiety may increase performance. Determining your own level of uncertainty and anxiety requires you to be aware of your own threshold levels. Perhaps the easiest method for determining threshold is through your physiological state. A few butterflies in your stomach increases your ICC, while none or too many decrease your ICC effectiveness. The trick is getting all the butterflies to go in the same direction.

\section{Adaptation Component}

Adaptation is often referred to as the adjustment to a new or unfamiliar situation or setting. Cultural adaptation occurs when one is willing to accept another culture's customs or worldview. Bennett and Bennett (2004) argue that "adaptation occurs when we need to think or act outside of our own cultural context" (p. 156). Adaptability is often referred to as behavioral flexibility (Bochner \& Kelly, 1974; Spitzberg \& Cupach, 1989). Having a diverse behavioral repertoire and knowing when to use it is key to adaptability in new situations. In addition, the authors 
contend that by taking the perspective of the other person, we can begin to feel and construct our identity from their viewpoint. This newly developed identity is an initial step in the integration process, which Kim discusses in her intercultural communication model.

Y. Kim's work that began in 1991 presents a model of ICC focusing on the immigrant and the acculturation of the immigrant to the new host culture. The idea that one must "adapt, adjust, or integrate" into the new cultural ways is essential for ICC. Although our focus is on a sojourner's approach to the intercultural interaction, within the negotiation context, Kim's principles of adaptation and integration are important in the development of long-term negotiation relationships (Kim, 2001).

The global marketplace requires us to think beyond the short-term outcome to the development of long-term relationships and even partnerships for survival in the global business community. The development of a "third culture" effect is highly likely if negotiating parties adapt and integrate their cultures' identities. This shift in identity happens over a period of successful and not-so-successful interactions in negotiation. As Neuliep (2003) suggests, intercultural competence means adapting verbal and nonverbal messages to the appropriate cultural context. As a result of this mutual adaptation in communication behavior, parties can then move to a discussion that reflects a transactional communication process that creates the third-culture phenomenon. As the business world becomes more sophisticated in adaptation and eventually integration, we would expect to see a transformation of how people conduct business in the global market. Perhaps the blurring of culture will result in a truly geocentric identity.

\section{Face Honoring and Protection}

Dignity and respect are all too often missing from business negotiations. Yet we know that human beings respond positively to others who demonstrate a positive regard for themselves and an appreciation for differences. Goffman (1959) introduced face as the wish to have a positive social impression on others. Face embodies the concept that individuals want to have others view them with respect and dignity. Facework is the behaviors and strategies we engage in to establish a positive face. Face and facework are two distinct concepts. Face is the individual's desire for a favorable impression, whereas facework is the "specific verbal and nonverbal behaviors that we engage in to maintain or restore face loss and to uphold and honor face gain" (Ting-Toomey, 2005, p. 73). The concept of face means different things depending on one's culture. For example, in China there are two types of face. There 
is lian (face), defined by $\mathrm{Hu}$ (1944) as "representing the confidence of society in the integrity of ego's moral character, the loss of which makes it impossible for him to function properly within the community" (p. 45). The second type of face in China is referred to as mian or mian zi (image), which means the status or prestige one receives for success in life (Hu, 1944; Oetzel et al., 2001). In every culture, face is considered an important factor in communicating with others. The degree of importance and the distinctive forms of face vary among cultures. For example, Japan has two types of face, mentsu (social status success) and taimen (self-presentation to others) (Morisaki \& Gudykunst, 1994). Part of face for all cultures is associated with one's honor, respect, and social interactions.

There are generally three orientations of face behavior: self-face (concern for one's own image), other face (concern for another person's image), and mutual face (concern for both self and other's image) (TingToomey \& Kurogi, 1998). Cultures vary in the level of importance they place in preserving these concerns. For example, in the United States, communication is typically more from a self-face concern, whereas in Mexico and Japan, communication focus tends to be from an other-face or mutual-face concern. It is important not only to consider what face concern one typically has, but also what one expects others to demonstrate. Clearly, one's orientation toward face, as well as the context in which the communication occurs, affects the strategies for issues relating to face. Let us take a closer examination of face strategies that negotiators may engage in during a global business negotiation.

\section{Types of Face Strategies}

Inherent in every interaction is face. We propose that there are three critical face strategies to consider in global business negotiation: faceprotection strategies, face-threatening strategies, and face-renovation strategies.

There are two types of face-protection strategies: protection of one's own face and protection for another's face. Self-protection face is reflected in messages that allow for one to defend or preserve his or her image to avoid any damage to face. Other-face protection strategies are messages that bolster the other's competency or trustworthiness to prevent damage to the other's face. Examples of such messages include deflections of embarrassment or shame from the other, providing rationale or justification in the circumstances, or pretending the incident didn't occur.

Face-threatening strategies entail attacking the other person's image. Often this occurs as an attempt to defend oneself when one perceives another acting aggressively, trying to dominate in order to 
exert more power, or trying to discredit one (e.g., saying something to make you look incompetent or dishonest). Face-threatening strategies are similar to Wilson and Putnam's (1990) face-attacking need. Face threatening includes not only verbal messages but also the role silence (invalidation) plays in threatening face. Silence as a face-threatening situation occurs quite often in the U.S. culture. For example, Ms. Tompkin, a negotiator for a food distribution company, is meeting with Mr. Jones and his sales team to renegotiate a contract agreement for the upcoming year. Ms. Tompkin is unhappy with the quality of service she has received from Mr. Jones. The meeting begins with Mr. Jones asking, "Haven't I done a great job of providing you with on-time deliveries?" Instead of responding to Mr. Jones's question, Ms. Tompkin remains silent. This silence in the U.S. business culture is viewed as embarrassment, or a way of devaluing Mr. Jones.

Face-renovation strategies are used when damage to one's face has already occurred and credibility and trust must be restored. Face renovation is also self and other oriented. That is, one can engage in selfface renovation by engaging in behaviors that others perceive as honest and competent. It is also possible to restore another's face by providing arguments or information that increases the other's credibility and sincerity or by using humor to deflect an embarrassing moment. Cupach and Imahori (1993) caution that humor is sensitive to one's culture and therefore requires care in its application. Even if a negotiator believes he or she has a sense of what is viewed as humorous in a specific culture, it is necessary to consider the individual differences in acceptable humor. Humor is typically revealed over a period of time as one develops a relationship with another person. We suggest relationship development becomes a key factor in how humorous attempts are interpreted-as face-attacking insults or laughable moments.

Face renovation allows for repair of damaged face to occur so that communication can continue in the intercultural relationship. For example, in self-face renovation, a negotiator may have a person who is highly respected by the other party speak on his behalf. Here is an example of other-face renovation. Assume the other's face has been damaged; perhaps he was caught in a dishonest statement. The other negotiator offers a reasonable explanation for his statement and suggests that it must all be a misunderstanding because the other is above reproach. Another tactic might be to cover his deception with another lie. For example, Negotiator Jim claims that your partner, Ted, has already agreed to buy his bolts for 2 million dollars. Just then, Ted walks in and hears this statement. Both Jim and Ted realize that the claim is untrue. However, Ted offers other-face renovation by stating, "I can't keep that agreement; can we discuss the price further?" Both 
parties know there was no agreement on price. However, by offering a face renovation, the parties are able to continue the negotiation without long-term damage. In fact, the relationship may be enhanced by the face-renovation gesture made by Ted. In cultures where face is very important and face damage has long-term effects, face renovation is an important strategy to have available.

\section{Face-Negotiation Theory}

Ting-Toomey's conflict face-negotiation theory (Ting-Toomey, 1985, 1988, 2004, 2005; Ting-Toomey \& Kurogi, 1998) makes an important contribution to understanding face in intercultural interaction. The significance of her contribution to face is important for our understanding of global business negotiations and therefore is briefly described in the following paragraphs.

This theory presents an integrative view of face negotiation, conflict, and culture (conflict face-negotiation theory; see Ting-Toomey, 2005). The seven core propositions follow.

1. People in all cultures try to maintain and negotiate face in all communication situations.

2. The concept of face is especially problematic in emotionally vulnerable situations (such as embarrassment, request, or conflict situations) when the situation identities of the communicators are called into question.

3. The cultural variability dimensions of individualism-collectivism and small/large power distance shape the orientations, movements, contents, and styles of facework.

4. Individualism-collectivism shapes members' preferences for selforiented facework versus other-oriented facework.

5. Small/large power distance shapes members' preferences for horizontalbased facework versus vertical-based facework.

6. The cultural variability dimensions, in conjunction with individual, relational, and situational factors influence the use of particular facework behaviors in particular cultural scenes.

7. Intercultural facework competence refers to the optimal integration of knowledge, mindfulness, and communication skills in managing vulnerable identity-based conflict situations appropriately, effectively, and adaptively.

SOURCE: From Ting-Toomey, S. (2005). 
These general theorems lay the framework for how face and facework strategies can help those who are intercultural negotiators. Culture and communication are intertwined, and face is always present in the communication process regardless of the issue. Within these propositions advanced by Ting-Toomey lie guidelines for international negotiators, especially when conflict arises.

In conflict situations such as negotiating a contract for $x$ number of goods or services between intercultural parties, face may be an integral part of the outcome. Negotiators must examine the role that face plays in their culture, the rules of appropriateness for face and preserving the other's face, the strategies that are likely to be used by one's self and the other party (individualistic versus collectivistic), as well as the conditions surrounding the negotiation episode. In addition, Ting-Toomey presents intercultural facework competence. Inclusive in her presentation of facework competence is the appropriateness, effectiveness, and adaptive (adaptability) behavior in intercultural conflictual situations (such as negotiations).

Following is a brief summary of Ting-Toomey's research comparing individualistic and collectivistic cultures. These have been paraphrased.

Individualistic cultures when compared to collectivistic cultures tend to

- express more self-maintenance concerns;

- use more direct, dominating facework strategies;

- use more dominating/competing conflict styles;

- use more emotionally expressive conflict styles; and

- use more assertive to aggressive conflict styles.

Collectivistic cultures compared to individualistic cultures tend to

- express more other-face concerns;

- express more mutual-face maintenance concerns;

- use more avoidance facework strategies;

- use a greater degree of integrative facework strategies;

- use more avoiding conflict styles;

- use more obliging conflict styles; and

- use more compromising to integrating conflict styles.

SOURCE: From Ting-Toomey, S. (2005). The matrix of face: An updated face-negotiation theory. In W. B. Gudykunst (Ed.), Theorizing about intercultural communication. Reprinted with permission of Sage Publications, Inc.

\section{Sensitivity and Empathy}

What does it mean to be a sensitive, empathetic individual in the intercultural interaction? We all like those who make us feel listened to, 
validated, and understood, and we dislike those who pretend to understand. Bennett and Bennett (2004) offer in their model of development of intercultural sensitivity that, "as one's experience of cultural difference becomes more sophisticated, one's competence in intercultural relations increases" (p. 152). We develop cognitively as well as behaviorally into a sensitivity of cultures that moves beyond our ethnocentric perspective of viewing others into an integrated view of others and self. This cannot be achieved by acquiring general knowledge about cultural generalities or by personal experience alone. Rather, competency is a result of a new cognitive structure that is authentic and global. The process of reframing one's perspective may lead to a global identity, thus creating a better opportunity for successful communication in the international business negotiation.

Empathy is an affective feeling. You can teach people to act empathetic but not to feel empathy. One way to enhance our ability to feel empathy toward other cultures is developing a physiologically connection. Bennett and Castiglioni (2004) suggest that to be interculturally communication competent, we need to know cognitively about another culture and generate the feeling for the other culture. They suggest, "With that feeling, behavior appropriate in the other cultural context can flow naturally from our embodied experience, just as it does in our own

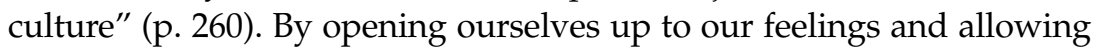
ourselves to experience what represents the other's cultural experiences, we are likely to gain valuable knowledge on how others different from us experience or feel life. This affective phenomenon provides opportunities in negotiation for enlightenment and recognition (Bush \& Folger, 1994), which ultimately lead to transformative agreements.

Sometimes individuals experience a great sense of difference from the other person and their culture. This experience can result in "culture shock." Empathy, as Redmond (2000) reported, increased the individuals' intensity of culture shock because they could recognize the differences between themselves and the other culture. A highly sensitive individual may have a culture shock response, but over time, the empathy may result in a much richer understanding and multilevel identity for the individual.

For example, Ms. Rudolph from England is negotiating with Mr. Yawlan from a small village in Zimbabwe. Ms. Rudolph arrives in the village, where she is to negotiate the mining of diamonds. She notices that around noon, everyone quits working and walks to an area outside the village. She assumes there must be some daily ritual that she is unfamiliar with. Ms. Rudolph mentions that to Mr. Yawlan, and Mr. Yawlan explains that the community members are going to bury 
their dead. Ms. Rudolph comments, "But I see this every day!” Mr. Yawlan simply responds with, "Yes, people are dying daily here from disease and malnutrition." Ms. Rudolph feels a true sense of the living tragedy that her business associate experiences regularly. Her response to this sense of overwhelming sadness may be a sense of isolation, guilt for her wealthy culture, detachment, or confusion by the way the village continues to function. These may all be signs of culture shock. Her sensitivity and empathy toward the village people may have intensified her view of the differences between her culture and theirs. However, this same sensitivity can make her a more competent communicator because of her heightened sense of awareness and authenticity or genuine connection to their grief.

The relationship that develops between Ms. Rudolph and Mr. Yawlan is in part a result of Ms. Rudolph's sensitivity and ability to empathize with Mr. Yawlan. The business relationship is enriched by her empathetic and sensitive communication about Mr. Yawlan's world that extends beyond the substantive issues. The end result is that a richer, culturally sensitive relationship may have emerged for both parties.

\section{Mindfulness or Being Present}

Mindfulness is a key factor in becoming interculturally communication competent (Langer, 1989; Ting-Toomey, 1999). Mindfulness, as described by Langer (1989), involves developing new categories, being open to new information, and being more aware of others' perspectives (p. 62). The Chinese word ting refers to "listening with your ears, eyes and one heart" (Ting-Toomey \& Kurogi, 1998, p. 204); this may best describe what we refer to as being mindful and present. Being able to imagine new solutions and reach creative agreements is essential in global business negotiations. Focusing on opportunities to see someone differently, or a willingness to think beyond the past roadblocks, requires negotiators to be present in the moments of the conversation. The negotiator must rely not on past scripts to get them to resolution but rather moments of creativity that are developed through mindful acts and thoughts. Bush and Folger (1994) describe this as transformative conflict resolution.

Ting-Toomey suggests engaging in "mindful reframing" as a strategy for managing skill in conflict resolution. She suggests that negotiators must be able to translate the other party's verbal and nonverbal messages from their cultural standpoint. Furthermore, acquiring the skill to listen during a conflict to the other party in a mindful and non-evaluative manner is important. This requires an individual to be 
attentive to underlying assumptions that are occurring during the interaction.

The concept of mindfulness is relatively new to Westerners, but many Eastern cultures embrace mindfulness as part of their cognitive practice in communicating with others. We have used the words be present in communicating and negotiating with others. Oftentimes we are thinking ahead to the next point we want to make or what strategy we will use, or we are even evaluating the individual's clothes instead of listening to the words and watching the expressions on the other party's face. Being present requires us to not think about ourselves, nor to be distracted by external psychological or environmental noises, but rather to search for meaning and commonness with the other person. The mindfulness of communication is choosing language that has taken into consideration the other person's culture, interacting with a multicultural identity, and embracing opportunities to act verbally and nonverbally in a reciprocal and thoughtful way. Mindfulness and presence are essential parts of the global business negotiation and are critical for creative and competent global business negotiators.

\section{Knowledge}

Knowledge about the other person's culture is a critical component of ICC. To truly share in meaningful discourse in intercultural negotiations, we must have knowledge about the other's religion, customs, values, language, and linguistic and politeness strategies. Competency is not simply learning a foreign language. One must have an understanding of how language is used to facilitate meaning appropriately. In addition, languages vary in terms of the amount of variation available to show respect and politeness (Dolinina \& Cecchetto, 1998). For example, English has few grammatical mechanisms for differentiating status, whereas Japanese has several grammatical structures for communicating politeness in regards to inequity, status, and power. Hazleton and Cupach (1986) conclude that we need to have knowledge about a variety of areas. For example, they suggest that ICC is more likely to occur if we know (a) what communication strategies will lead to achieving our goals, (b) the rules that govern the appropriateness of messages in the specific context, (c) the possible consequences that might occur if we deviate from the rules, and (d) how to create meaningful messages given the other's cultural perspective.

There are several different but related types of knowledge that aid in the development of ICC in global negotiations. First, Hazelton and Cupach present linguistic knowledge (Chen \& Starosta, 1996, referred to 
as linguistic competency), which is concerned with how cultures assemble their messages, how they grammatically construct their sentences, and the degree to which the word provides the meaning. Second, knowing how and when to speak and how to read, and being able to mindfully listen and understand the other culture's language is another important aspect (Redmond, 2000). Research has shown that fluency in speaking the other party's language is important in effective communication (Martin \& Hammer, 1989; Ting-Toomey \& Korzenny, 1989).

A third important level of knowledge is ontological knowledge (Hazelton \& Cupach, 1986). They describe ontological knowledge as being "reflected in communicators' ability to describe, predict, and explain human behavior" (p. 120). The way in which we know something is reflected is our view of reality. This level of knowledge has to do with the interpretation level of meaning. For example, cultures vary in their conceptualization of communication competency. In Asian cultures such as China, creating harmony is viewed as a key element in competently communicating. In Korea, communication competency is the ability to express messages indirectly and transcendentally (Chen \& Starosta, 1996).

A fourth type of knowledge is knowledge about the business negotiation process. One has to understand the construction of the negotiation within a given culture. Both the structure and the process for interacting in the negotiation are relevant information for successful interactions, especially during international business transactions.

For example, when purchasing a basket in Mexico, it is expected that the negotiation process occurs something like this:

Person A: How much for the basket?

Person B: (always ask more than you want) \$200.

Person A: (always counteroffer) Oh, would you be willing to take $\$ 50$ ?

Person A: Oh, I cannot do that. It is a one of a kind. How about $\$ 150$ ?

Person B: (you want to provide some face saving but not give him the price) I will give you $\$ 75$.

Person A: I cannot sell it for that.

Person B: (walks away)

Person A: (yells) Okay! I will give it to you for $\$ 100$.

Person B: (comes back to A and buys the basket for \$100) 
This same business transaction would follow a very different process were it to happen in a U.S. shopping mall. The negotiation would be like this.

Person A: How much for the basket?

Person B: Let's see, is the price marked? Oh, here it is: \$200.

Person A: Will this basket go on sale anytime soon?

Person B: No, but if you open a credit card account, I can give you 15 percent off today.

Person A: Okay. What do I need to do?

The important difference between the two examples is that the first relies heavily on the relationship aspect of negotiating. The price isn't marked and the communication strategy influences the interaction that ultimately leads to the purchase. The second example is based on the substantive issue of price. The price marked ahead of time is the basis for the negotiation. The relationship (e.g., the credit card) only becomes a possible influencing factor if the price is not acceptable. Thus, if one tries to negotiate in the second example by using the strategies employed in the first, it is highly unlikely that the store clerk would call out to the customer who is unwilling to pay the marked price. A negotiator who can successfully negotiate in either cultural setting is more interculturally competent because he or she has the knowledge about the different cultural communication norms and he or she has the repertoire of strategies from which to select. Furthermore, he or she has the ontological knowledge of human behavior. This, coupled with knowledge of the business negotiation process of the cultural context, leads him or her to achieve his or her goal-buying the basket.

\section{Assessing Competency}

There has been a great deal of discussion on assessing communication competency. Some scholars have contended that communication competency is a trait (McCroskey, 1984) and can best be assessed by selfreport measures. For example, in a study that used a self-assessment measure of competency, Swedes were higher in competency than Americans (McCroskey, Burroughs, Daun, \& Richmond, 1990). Others argue that communication competency is situation based and must be judged from the receiver's perspective (Rubin, 1982). Others present an 
interactional approach suggesting that communication competency is a product of both trait and situation.

We contend that ICC is influenced by individual predispositional factors (e.g., communication apprehension, argumentativeness, etc.). However, more important is the negotiator's specific knowledge, skill, and motivation (Rubin, 1985; Spitzberg, 1983) for communicating internationally. Knowledge, skill, and motivation are necessary criteria for ICC. Communication norms are culture-bound, and therefore competency is a function of culture and it is how we are evaluated in the interaction that ultimately determines ICC. As Phillips comments, "'competence' is not a 'thing.' It is an evaluation" (1983, p. 25). We now turn to how these components lead to communication competent negotiators.

To be a competent intercultural communicator requires knowledge and performance or, put another way, cognitive ability as well as skill. Without knowledge (e.g., linguistic, ontological, cultural, negotiation), skill (e.g., appropriate and effective strategy selection, empathic listening), or motivation (e.g., uncertainty, communication apprehension), communication competency is not likely to be achieved. For example, Mr. Dufour, buyer for ATI Electronique Company based in France, is going to meet with Mr. Lee, a seller from Delphi Corporation, based in South Korea. Mr. Lee has knowledge about the French culture and about ATI Electronique's organizational culture, goals, and management style, and he speaks fluent French. He considers himself well prepared and appears motivated to negotiate with Mr. Dufour. It appears that Mr. Lee is communication competent for this meeting (at least on the cognitive dimension of communication competency).

However, Mr. Lee is very anxious or has a high degree of uncertainty about meeting with someone different from himself. He is feeling more anxious than usual because he has heard that Mr. Dufour does not "fit" the cultural generalities of the French businessperson. This creates a skill deficiency in Mr. Lee's communication competency because his anxiety reduces his motivation and affects his ability to communicate competently. Therefore, although Mr. Lee is knowledgeable and appears motivated to negotiate, his competency in this intercultural business negotiation is compromised because of his high level of anxiety.

We could easily have adjusted this example to reflect knowledge as the deficient factor and the results would be the same. The key to successful ICC is that one must be motivated, knowledgeable, and skilled to be a successful and competent communicator in the global marketplace. These three general factors are interrelated in that a deficiency in 
one impacts at least one of the other components. The deficiency reduces the likelihood of achieving a high level of ICC. Spitzberg (1991b) points out in his model of interpersonal communication competency that there is an additive effect of these three factors, resulting in "communication satisfaction, perceived confirmation, and conversational appropriateness and effectiveness" (p. 22).

\section{* CONCLUSION}

We propose that communication competency in the intercultural business negotiation context is influenced by communication abilities, culture of origin, importance of the negotiation relationship, knowledge of other cultures reflected in the global business community, and the motivation and skills to negotiate. In addition, highly competent negotiators will possess a multicultural knowledge base that they embrace as part of their identity. This restructuring of how they view themselves and others results in a multicultural identity. This multicultural identity as described by Bennett and Bennett is a result of cognitive restructuring, which leads to an integration stage in cultural sensitivity.

The "appropriateness" of the communicative message is highly influenced by the cultural rules and norms. It is essential that the international negotiator have the cultural knowledge about the other party as well as knowledge about the other party's individual communication style to communicate in an appropriate manner. Remember, it is the combination of cultural knowledge plus individual knowledge that optimizes the chances for successful communication and ultimately an effective negotiated agreement.

Much of the discussion to this point has focused on each individual element that enhances a negotiator's ICC. Intercultural communication competency is both an individual-based and interaction-based concept. The individual's skills and predispositions may help him or her achieve a higher level of competency, but it is the interaction that occurs between the negotiating parties that ultimately determines ICC. An individual can have all the training, knowledge, and motivation to communicate, yet fail in communicating competently with another. The interactional effect created by the two parties ultimately determines competency. Thus, although this chapter presents key factors in optimizing ICC for the individual, we must always be cognizant of the dynamics of discourse, especially in intercultural problem-solving settings such as global business negotiations. Ultimately, ICC in the business negotiation is heavily reliant on the mutual understanding of the 
negotiation process and the other person. In addition, we must also recognize that communication competency is conceptualized differently in other cultures. We have addressed the common elements in communicating in intercultural business negotiations. Sensitivity to how different cultures conceptualize communication competency within their own culture is always an important variable.

\section{* GUIDELINES FOR GLOBAL NEGOTIATION SUCCESS}

There are 12 communication guidelines that should be followed when entering into global business negotiations. Competency is the most important factor for obtaining a successful agreement.

1. Do I have the necessary information about the other party's culture, individual style, and the negotiation process to communicate verbally and nonverbally in a sensitive, mindful, appropriate manner?

2. Do I have the knowledge and the ability to listen for opportunities for common ground to be established and shared interests to emerge?

3. What is my level of competency in the other party's native language and interpretation of meaning?

4. How can I allow for face saving when conflict arises?

5. What face-saving strategies do I know how to use, and do I know when to use them?

6. How do I establish a relationship with the other party, knowing that relationship is interpreted differently in various cultures? For example, formal, hierarchical structure is an important component of developing a working relationship in Japan; whereas informal, equal status is assumed among various levels of authority in the United States.

7. What goals do I want to achieve in the negotiation? Do I have a diverse repertoire of strategies and tactics to facilitate a meaningful discussion with the other party?

8. What role does silence play in the negotiation process?

9. What is my threshold level of uncertainty with negotiating with the other party? 
10. Do I have a wide range and number of behaviors and am I comfortable using them?

11. Am I flexible in my behaviors?

12. Am I able to stay focused and present when I am interacting with others without making judgments or evaluations?

\section{DISCUSSION QUESTIONS}

1. What key factor is the most important to successful ICC? Explain your answer.

2. How does face affect the communication competency of a global negotiator?

3. What projections would you make about the role of ICC for the next generation?

4. What are the critical components of individual success in the international marketplace?

5. How can you best prepare for the evolving global marketplace?

6. What critical communication skills are necessary for international negotiation?

7. What difficulty lies ahead for those who remain focused on cultural differences rather than individual differences?

\section{REFERENCES}

Bennett, J. M., \& Bennett, M. J. (2004). Developing intercultural sensitivity: An integrative approach to global and domestic diversity. In D. Landis, J. M. Bennett, \& M. J. Bennett (Eds.), Handbook of intercultural training (3rd ed., pp. 147-165). Thousand Oaks, CA: Sage.

Bennett, M. J., \& Castiglioni, I. (2004). Embodied ethnocentrism and the feeling of culture: A key to training for intercultural competence. In D. Landis, J. Bennett, \& M. Bennett (Eds.), Handbook of intercultural training (3rd ed., pp. 249-265). Thousand Oaks, CA: Sage.

Berger, C. R., \& Calabrese, R. (1975). Some explorations in initial interaction and beyond: Toward a developmental theory of interpersonal communication. Human Communication Research, 1, 99-112.

Bochner, A., \& Kelly, C. (1974). Interpersonal competence: Rationale, philosophy, and implementation of a conceptual framework. Speech Teacher, 23, 279-301. 
Bush, R. A. B., \& Folger, J. P. (1994). The promise of mediation, responding to conflict through empowerment and recognition. San Francisco: Jossey-Bass.

Cai, D. A., Wilson, S. R., \& Drake, L. E. (2000). Culture in the context of intercultural negotiation: Individualism-collectivism and paths to integrative agreements. Human Communication Research, 26, 591-617.

Chen, G., \& Starosta, W. J. (1996). Intercultural communication competence: A synthesis. Communication Yearbook, 19, 353-383.

Cupach, W. R., \& Canary, D. (Eds.). (1997). Competence in interpersonal conflict. New York: McGraw-Hill.

Cupach, W. R., \& Imahori, T. T. (1993). Managing social predicaments created by others: A comparison of Japanese and American facework. Western Journal of Communication, 57, 431-444.

Cupach, W. R., \& Spitzberg, B. H. (1981, February). Relational competence: Measurement and validation. Paper presented at the Western Speech Communication Association, San Jose, CA.

Cupach, W. R., \& Spitzberg, B. H. (1983). Trait versus state: A comparison of dispositional and situational measures of interpersonal communication competence. Western Journal of Speech Communication, 47, 364-379.

Dolinina, I. B., \& Cecchetto, V. (1998). Facework and rhetorical strategies in intercultural argumentative discourse. Argumentation, 12(2), 117-135.

Fisher, R., Ury, W., \& Patton, B. (Ed.). (1991). Getting to yes, negotiating agreement without giving in (2nd ed.). New York: Penguin Books.

Goffman, E. (1959). The presentation of self in everyday life. Garden City, NJ: Doubleday.

Gudykunst, W. B. (1998). Bridging differences: Effective intergroup communication (3rd ed.). Thousand Oaks, CA: Sage.

Gudykunst, W. B. (Ed.). (2005). Theorizing about intercultural communication. Thousand Oaks, CA: Sage.

Hampden-Turner, C., \& Trompenaars, F. (2000). Building cross-cultural competence: How to create wealth from conflicting values. New Haven, CT: Yale University Press.

Hazleton, V., Jr., \& Cupach, W. R. (1986). An exploration of ontological knowledge: Communication competence as a function of the ability to describe, predict, and explain. Western Journal of Speech Communication, 50, 119-132.

Hofstede, G. (1980). Culture's consequences: International differences in workrelated values. Beverly Hills, CA: Sage.

Hu, H. C. (1944). The Chinese concepts of "face." American Anthropologist, 46, 45-64.

Kim, M. (1993). Culture-based conversational constraints in explaining crosscultural strategic competence. In R. L. Wiseman \& J. Koester (Eds.), Intercultural communication competence (pp. 132-150). Newbury Park, CA: Sage.

Kim, M. (1994). Cross-cultural comparisons of the perceived importance of conversational constraints. Human Communication Research, 21, 128-151.

Kim, M., \& Wilson, S. R. (1994). A cross-cultural comparison of implicit theories of requesting. Communication Monographs, 61, 210-235. 
Kim, Y. Y. (2001). Becoming intercultural: An integrative theory of communication and cross-cultural adaptation. Thousand Oaks, CA: Sage.

Klopf, D. W. (2001). Intercultural encounters: The fundamentals of intercultural communication (5th ed.). Inglewood, CA: Morton.

Landis, D., Bennett, J. M., \& Bennett, M. J. (Eds.). (2004). Handbook of intercultural training (3rd ed.). Thousand Oaks, CA: Sage.

Langer, E. (1989). Mindfulness. Reading, MA: Addison-Wesley.

Martin, J. N., \& Hammer, M. R. (1989). Behavioral categories of intercultural communication competence: Everyday communicators' perceptions. International Journal of Intercultural Relations, 13, 303-332.

McCroskey, J. C. (1984). The communication apprehension perspective. In J. A. Daly \& J. C. McCroskey (Eds.), Avoiding communication: Shyness, reticence and communication apprehension (pp. 13-38). Beverly Hills, CA: Sage.

McCroskey, J. C., Burroughs, N. F., Daun, A., \& Richmond, V. P. (1990). Correlates of quietness: Swedish and American perspectives. Communication Quarterly, 38(2), 127-137.

Morisaki, S., \& Gudykunst, W. B. (1994). Face in Japan and the United States. In S. Ting-Toomey (Ed.), The challenge of facework: Cross-cultural and interpersonal issues (pp. 47-94). Albany: State University of New York.

Neuliep, J. W. (2003). Intercultural communication: A contextual approach (2nd ed.). Boston: Houghton Mifflin.

Oetzel, J., Ting-Toomey, S., Masumoto, T., Yokochi, Y., Pan, X., Takai, J., \& Wilcox, R. (2001). Face and facework in conflict: A cross-cultural comparison of China, Germany, Japan, and the United States. Communication Monographs, 68(3), 235-258.

Parks, M. R. (1985). Interpersonal communication and the quest for personal competence. In M. L. Knapp \& G. R. Miller (Eds.), Handbook of interpersonal communication (pp. 171-201). Beverly Hills, CA: Sage.

Phillips, G. M. (1983). A competent view of "competence." Communication Education, 32, 25-36.

Philipsen, G. (1992). Speaking culturally: Explorations in social communication. New York: State University of New York at Albany Press.

Philipsen, G. (1997). Speech codes theory. In G. Philipsen \& T. Albrecht (Eds.), Developing theories of communication. New York: State University of New York at Albany Press.

Redmond, M. V. (2000). Cultural distance as a mediating factor between stress and intercultural communication competence. International Journal of Intercultural Relations, 24, 151-159.

Rubin, R. B. (1982). Assessing speaking and listening competence at the college level: The communication competency assessment instrument. Communication Education, 31, 9-18.

Rubin, R. B. (1985). The validity of the communication competency assessment instrument. Communication Monographs, 52, 173-185.

Salacuse, J. (1991). Making global deals. Boston: Houghton Mifflin. 
Snavely, W. B., \& Walters, E. V. (1983). Differences in communication competence among administrator social styles. Journal of Applied Communication Research, 11(2), 120-135.

Spitzberg, B. H. (1983). Communication competence as knowledge, skill, and impression. Communication Education, 32, 323-329.

Spitzberg, B. H. (1991a). Intercultural communication competence. In L. A. Samovar \& R. E. Porter (Eds.), Intercultural communication: A reader (pp. 353-365). Belmont, CA: Wadsworth.

Spitzberg, B. H. (1991b). An examination of trait measures of interpersonal competence. Communication Reports, 4(1), 22-30.

Spitzberg, B. H., \& Cupach, W. R. (1984). Interpersonal communication competence. Beverly Hills, CA: Sage.

Spitzberg, B. H., \& Cupach, W. R. (1989). Handbook of interpersonal competence research. New York: Springer-Verlag.

Ting-Toomey, S. (1985). Toward a theory of conflict and culture. In W. Gudykunst, L. Stewart, \& S. Ting-Toomey (Eds.), Communication, culture, and organizational processes (pp. 71-86). Beverly Hills, CA: Sage.

Ting-Toomey, S. (1988). Intercultural conflict styles: A face-negotiation theory. In Y. Y. Kim \& W. B. Gudykunst (Eds.), Theories in intercultural communication (pp. 213-238). Newbury Park, CA: Sage.

Ting-Toomey, S. (1999). Communicating across cultures. New York: Guilford Press.

Ting-Toomey, S. (2004). Translating conflict face-negotiation theory into practice. In J. M. Bennett, M. J. Bennett, \& D. Landis (Eds.), Handbook of intercultural training (3rd ed., pp. 217-248). Thousand Oaks, CA: Sage.

Ting-Toomey, S. (2005). The matrix of face: An updated face-negotiation theory. In W. B. Gudykunst (Ed.), Theorizing about intercultural communication. Thousand Oaks, CA: Sage.

Ting-Toomey, S., \& Korzenny, F. (Ed.). (1989). Language, communication, and culture: Current directions. Newbury Park, CA: Sage.

Ting-Toomey, S., \& Kurogi, A. (1998). Facework, competence in intercultural conflict: An updated face-negotiation theory. International Journal of Intercultural Relations, 22(2), 187-225.

Wiemann, J. M. (1977). Explication and test of a model of communication competence. Human Communications Research, 3, 195-213.

Wilson, S. R., \& Putnam, L. L. (1990). Interaction goals in negotiation. In J. A. Anderson (Ed.), Communication yearbook 13 (pp. 374-427). Newbury Park, CA: Sage. 
